\title{
LOS HASHTAGS EN EL DISCURSO INSTITUCIONAL ESPAÑOL SOBRE LA COVID-19 EN TWITTER
}

\author{
Ana Pano Alamán \\ Università di Bologna \\ ana.pano@unibo.it \\ https://orcid.org/0000-0003-3652-8694
}

Resumen: En este trabajo se presentan los resultados de un análisis pragmalingüístico de un corpus de hashtags contenidos en los tuits publicados desde marzo de 2020 hasta mayo de 2021 en los perfiles del gobierno español, el ministerio de sanidad y el de salud pública. El estudio tiene como objetivos identificar las semejanzas y diferencias que presentan las etiquetas relacionadas con la Covid-19 en estas tres cuentas y determinar qué papel ha jugado este dispositivo en el discurso público institucional sobre la crisis pandémica. Los resultados muestran que existen diferencias respecto a la cantidad de etiquetas empleadas, mientras que, formal y funcionalmente, se utilizan de manera similar para contextualizar el mensaje y para informar y persuadir a los ciudadanos.

Palabras clave: discurso institucional, comunicación de crisis, Twitter, hashtag

Title: Hashtags in the Spanish institutional discourse about Covid-19 on Twitter

\begin{abstract}
This paper presents the results of a pragmalinguistic analysis of the hashtags included within the tweets published in the profiles of the Spanish government, the Ministry of Health and the Public Health agency from May 2020 to May 2021. The study aims at identifying the linguistic formal and content similarities and differences of the hashtags related to the Covid-19 disease, that were used within these accounts, and determining the role played by this affordance in the Spanish public institutional discourse about the pandemic. The results show that there are significant differences regarding the number of hashtags used, while, formally and functionally, they are used in a similar way in order to contextualize the message, and to inform and persuade citizens.
\end{abstract}

Keywords: institutional discourse, crisis communication, Twitter, hashtag 


\section{INTRODUCCIÓN}

La investigación sobre discurso público institucional en español se ha centrado en los últimos meses en la estrategia y gestión comunicativa de la crisis sanitaria provocada por la Covid-19 (Ibáñez Peiró, 2020; Casero-Ripollés, 2020; Gutiérrez-Rubí y Pont-Sorribes, 2020; Castillo-Esparcia et al., 2020; López-García, 2020; Pulido-Polo et al., 2021, entre otros). En gran parte de estos estudios, se aborda la comunicación de crisis en los medios de comunicación, especialmente en la prensa, y en las redes sociales como Twitter, a partir del número de mensajes publicados por día, su contenido (información, ruedas de prensa, publicidad, agenda), el formato (texto, imagen, vídeo o enlace) y el nivel de interacción del contenido publicado, en los perfiles del gobierno y los ministerios encargados de gestionar algunos aspectos de la crisis, con los usuarios en esa plataforma. El nivel de interacción suele medirse a través del análisis del número de likes que reciben los mensajes institucionales, de retuits y de respuestas.

Uno de los dispositivos que caracterizan la interacción en Twitter, esto es, el hashtag o etiqueta, se queda generalmente fuera de este tipo de análisis, aunque investigaciones previas sobre la comunicación institucional en torno a otras emergencias (Calleja, 2016; Suau-Gomila, 2017; Tirado, 2018) han señalado el papel relevante que tiene este dispositivo en la gestión comunicativa de una crisis. Los hashtags, empleados a menudo en Twitter o en Instagram, aunque se extienden también a otras plataformas digitales (Salazar, 2017), son metadatos explícitos integrados en el mensaje, mediante los cuales se señala el tema o temas del tuit y se conecta ese mensaje a otros que contienen esa misma etiqueta. En general, están formados por palabras o secuencias de palabras precedidas de la almohadilla (\#), que se convierten en hiperenlaces una vez insertados en el mensaje. De este modo, amplían el significado potencial del tuit, pues gracias al enlace que genera, se conecta con otros mensajes fomentando un "ambiente de afiliación" entre los usuarios (Zappavigna, 2011).

El objetivo de este estudio es contribuir desde la lingüística a la investigación sobre el papel que tiene este dispositivo en el discurso público político-institucional, en concreto, en los mensajes que las instituciones españolas han publicado en Twitter durante la gestión de la pandemia de Covid-19. En este trabajo, se presentan los resultados de un análisis comparado de las etiquetas empleadas en los perfiles del gobierno español, el ministerio de Sanidad y el de Salud pública, cuenta oficial del gobierno con información de interés para la ciudadanía sobre cuestiones de salud. El estudio busca dar respuesta a las preguntas: ¿cuáles han sido las etiquetas más empleadas por estas instituciones en los últimos meses?; ¿qué rasgos lingüísticos presentan?; y ¿qué funciones discursivas desempeñan en relación con la gestión de la crisis sanitaria por parte de las autoridades? En primer lugar, se revisan los principa- 
les aspectos teóricos relacionados con la comunicación institucional, especialmente en periodos de crisis, y con el uso de este dispositivo en la comunicación política y gubernamental; en segundo lugar, se presentan la metodología y los datos en los que se basa el estudio; en tercer lugar, se ilustran y discuten los resultados; por último, se aportan algunas reflexiones sobre el alcance de la investigación.

\section{MARCO TEÓRICO}

La labor informativa del Estado adquiere una gran importancia en situaciones extraordinarias o de emergencia, como la que se produjo hace poco más de un año con la crisis que se generó en todo el mundo por la pandemia del coronavirus SARS-CoV-2 y que provocó la enfermedad Covid-19. En estos casos, la actividad comunicativa constituye uno de los tres pilares sobre la que se basa la respuesta de los gobiernos a las emergencias (cfr. Moreno, 2008). El primer elemento es el mando único, que en España está recogido en las medidas provisionales para la actuación en situaciones de emergencia en casos de grave riesgo, catástrofe o calamidad pública (R.D. 1378, 1985, Art. 8). El segundo es un sistema de comunicación y transmisión de datos, cuyo objetivo es la rápida acción de mando y control en la respuesta. El tercero está representado por una adecuada gestión de la información dirigida a los ciudadanos y a los medios de comunicación social a través del empleo de un plan de comunicación. Desde un punto de vista normativo, la administración está obligada a difundir "de forma periódica y actualizada la información cuyo conocimiento sea relevante para garantizar la transparencia de su actividad relacionada con el funcionamiento y control de la actuación pública” (Ibáñez Peiró, 2020: 306). No en vano, el discurso institucional del gobierno debería establecer un canal directo con los medios y con la ciudadanía además de definir el marco del debate, proporcionando, según Castillo-Esparcia et al., (2020: 3), información veraz y datos contrastados. Asimismo, es fundamental que la estrategia adoptada fomente empatía con los actores implicados en la pandemia, como las personas contagiadas u otros colectivos públicos, los sanitarios o las fuerzas de seguridad del Estado; la participación de los expertos en los procesos de decisión; el empleo de canales adecuados a los objetivos comunicativos que se establecen, a través de los cuales sea posible adaptar los mensajes a públicos diversos.

Como apunta Casero-Ripollés (2020), desde que se declaró el estado de emergencia nacional en marzo de 2020, la información se ha convertido en un bien preciado para hacer frente a la situación, puesto que "Las prácticas informativas tienen importantes repercusiones no sólo en el conocimiento que los ciudadanos tienen 
de su realidad inmediata, sino también en términos democráticos, debido a los estrechos vínculos entre la información y la democracia" (Casero-Ripollés, 2020: 2).

A partir de ese momento, se multiplican las comparecencias públicas, en su mayoría ruedas de prensa en las que el presidente y los ministros han tenido una presencia constante, y cuyo objetivo era ofrecer información de forma permanente, configurando de este modo una estrategia de agenda-setting y de encuadre. López-García (2020: 2) sintetiza las estrategias de comunicación adoptadas por el gobierno frente a la crisis sanitaria en: 1) la comunicación continua y constante a lo largo de toda la crisis (e.g. ruedas de prensa diarias del Comité de Gestión Técnica de la crisis, liderado por Fernando Simón, comparecencias diarias de ministros del gobierno, como el de sanidad, Salvador Illa; y semanales del presidente del gobierno Pedro Sánchez; b) el énfasis sobre la gravedad de la crisis, a partir de la instauración del estado de alarma con medidas restrictivas de las libertades ciudadanas, y como mecanismo de concienciación social; 3) la adopción de discursos que vehiculaban la percepción de que el Gobierno controlaba la crisis; 4) la apelación a la unidad y a la superación de discrepancias políticas. En este contexto, se configuró también un sistema mediático híbrido (Chadwick, 2013) en el que los medios tradicionales y los digitales se realimentaron mutuamente.

En lo que respecta a las redes sociales, Twitter fue la plataforma que concentró el mayor número de mensajes institucionales en los primeros meses de gestión de la crisis sanitaria. Y es que "por su carácter abierto, su capacidad para fijar la agenda y captar la atención del público, así como por su naturaleza (mensajes breves, que se difunden rápidamente y que pueden viralizarse a través de vías muy diversas)" (López-García, 2020: 5), constituye una de las redes mejor adaptadas a la interrelación entre políticos, medios y ciudadanos dentro de un mismo espacio. El éxito de Twitter en la comunicación institucional se sustenta en su capacidad de generar con la ciudadanía un sistema de comunicación dialógico (Camilleri, 2020), directo y ágil, que permite compartir información relevante de forma inmediata en situaciones de crisis (cfr. Pulido-Polo et al., 2021: 3-4).

Como han señalado los estudios mencionados, a partir del 13 de marzo de 2020, la evolución de la crisis intensifica el empleo del microblog por parte del gobierno (perfil @desdelamoncloa), que pasa de 7 tuits ese día a 46 el 31 de marzo, fecha en que el Consejo de Ministros aprueba un primer conjunto de medidas para luchar contra las consecuencias sociales de la crisis; la actividad media del gobierno en Twitter es de 17,1 publicaciones por día (Castillo-Esparcia et al., 2020: 9). Respecto a la interacción con los ciudadanos, esta se concentró durante los primeros quince días del estado de alarma (14-15 de marzo) y los primeros días de vigencia del confinamiento (22-28 de marzo), cuando se supera la barrera de los 2.000 likes y los 1.500 retuits. En concreto, el contenido que mayor impacto tuvo entre los usuarios 
fue un vídeo de dos minutos retuiteado el 22 de marzo por Moncloa desde la cuenta de Salud Pública (@SaludPublicaES), que recibió 11.900 likes y 6.900 retuits. En él, Simón explica las diferencias entre España y China a la hora de abordar la crisis. Por el alto número de likes (2.500) y retuits (1.700) recibidos destaca también un mensaje de Moncloa en el que aparece el cartel de la campaña "Este virus lo paramos unidos", así como las llamadas a no viajar, permanecer en casa y no compartir noticias falsas. De acuerdo con el mismo estudio (Castillo-Esparcia et al., 2020: 8), la información, la comunicación de servicio y la reproducción íntegra de las ruedas de prensa fueron los contenidos que predominaron en Twitter. Asimismo, el $81 \%$ de los tuits incorporó imágenes o vídeos, enlaces a webs como la de la presidencia del gobierno y de otros ministerios y organismos públicos, que permitían ampliar la información que se difundía en las redes. Sin embargo, Castillo-Esparcia et al. (2020: 19) concluyen que en este caso se produjo una disonancia entre las estrategias aplicadas en las ruedas de prensa y las aplicadas en las redes. Si bien el tema de los bulos sobre el coronavirus y su gestión y la apelación a recurrir a fuentes oficiales y fiables para informarse fueron centrales en el mensaje del ejecutivo en sus comparecencias públicas, se trata de un contenido que apenas tuvo presencia en Twitter.

Con un foco en los perfiles de Twitter del gobierno español y de los ministerios de Sanidad, Defensa, Interior y Transportes, Movilidad y Agenda Urbana, el análisis de Pulido-Polo et al. (2021) investiga las tasas de apoyo (likes), viralización (retuits), "conversación" (respuestas por parte de los usuarios en Twitter) y engagement, suma de las anteriores, obtenidas por estas cuentas. Los resultados muestran que los mensajes que utilizaban contenidos multimodales (vídeos) generaron, especialmente en la cuenta del ministerio de Sanidad, un mayor número de likes, retuits y respuestas. Asimismo, el comportamiento comunicacional de los ministerios se ajustó a las recomendaciones emitidas por la Organización Mundial de la Salud relativas a las etapas de gestión de la crisis, posicionándose como fuentes de información pública constante y fiable (Pulido-Polo et al., 2021: 10).

\subsection{Hashtag y discurso público institucional en Twitter}

Cuando un usuario de Twitter inserta en su mensaje una palabra, un sintagma o una oración precedidos de \#, crea una etiqueta que se convierte en un hiperenlace, dando así acceso a cualquier otro mensaje que contenga la misma etiqueta y permitiendo a cualquier usuario del microblog encontrar contenido relacionado con el tema que vehicula, en una red en la que los mensajes pueden acumularse rápidamente en un mismo espacio (Mancera Rueda y Pano Alamán, 2013; Page, 2014). Sin embargo, los usuarios lo emplean también como un medio a través del cual pueden destacar o poner 
de relieve un elemento lingüístico del mensaje. De hecho, el signo \# es un dispositivo semiótico complejo que establece distintos tipos de relaciones con el resto de los constituyentes del tuit. Menna (2012: 49) indica tres tipos de relaciones: interna, referida a la vinculación de la etiqueta con los elementos lingüísticos del mensaje; externa, que alude a las relaciones posibles entre el contenido del mensaje en que aparece la etiqueta y el contenido de los mensajes que también la utilizan; y contextual, que es la relación que se establece entre una unidad significante, en este caso un tuit, y el contexto situacional al que remite, invitando al destinatario a interpretar el sentido del mensaje a partir de los conocimientos que comparte con el emisor (cfr. Heyd y Puschmann, 2017: 56). En este sentido, Scott afirma que:

Hashtags provide a means by which tweeters can activate relevant contextual assumptions within the character limit and without the need to provide explicit background information and thus detract from the casual, informal style. In sum, hashtags can be used to activate certain contextual assumptions, thus guiding the reader's inferential processes (2015: 19).

La inclusión de un hashtag permite, en este sentido, aumentar la accesibilidad de ciertos supuestos sin incluir contenido adicional en el cuerpo principal del enunciado.

Estos aspectos han sido puestos en evidencia en diversos estudios sobre discurso público institucional en Twitter. En el ámbito del español, cabe señalar, entre otros, los trabajos sobre el discurso de los cuerpos de seguridad (Bani, 2020) o los ayuntamientos (Carratalá y Galán, 2016). Por ejemplo, Bani analiza el empleo de las etiquetas en los perfiles oficiales de la policía española, mexicana y argentina, llegando a la conclusión que las tres cuentas "aprovechan las etiquetas virales para entrar en una conversación global, ganar más visibilidad y conquistar a más seguidores” (Bani, 2020: 78, cursiva nuestra). Las más frecuentes son las que se refieren a conmemoraciones y días especiales, empleadas en mensajes cuya función principal es fática; otras se colocan en aposición al inicio o al final del tuit, con funciones temático-informativas.

El análisis de las etiquetas en Twitter se ha llevado a cabo sobre todo en el campo de la comunicación política (Mancera Rueda y Helfrich, 2014; Mancera Rueda y Pano Alamán, 2013, 2015; González Bengoechea, 2015; Gallardo-Paúls y Enguix Oliver, 2016; Más-Manchón y Guerrero, 2019). De acuerdo con estas investigaciones, los hashtags utilizados por los partidos y líderes políticos, generalmente en campaña electoral, permiten clasificar los tuits en mensajes de apoyo y mensajes de crítica hacia el gobierno, así como vehicular mensajes persuasivos para ganarse a los usuarios en esa red social. Mediante este dispositivo, que aparece a menudo insertado en el enunciado principal del tuit o desvinculado de él, a modo de cierre, los 
políticos elaboran una "retórica de la persuasión" destinada a los propios seguidores (Mancera Rueda y Helfrich, 2014: 83). Las que aparecen al final del mensaje, sin integración sintáctica con el resto de elementos verbales, se visualizan rápidamente resumiendo el contenido del tuit (Pano Alamán, 2020: 53). En todo caso, funcionan como consignas, puesto que, mediante la activación de ciertas implicaturas, buscan obtener una reacción en el destinatario que lo lleve a identificarse o a respaldar lo que plantea el emisor político. Y es que la etiqueta, como el eslogan, designa "una fórmula concisa, fácil de retener y de repetir, que implica o connota y sugiere más que lo que realmente dice o denota" (López Eire, 1998: 43). En este sentido, su capacidad evocativa responde a una intención persuasiva.

\section{Metodología y Corpus}

Con el objeto de indagar sobre el comportamiento discursivo de las etiquetas en los mensajes publicados en los perfiles del gobierno en Twitter (@desdelamoncloa,@sanidadgob,@SaludPublicaEs)dedicados a la gestión informativa de la crisis sanitaria, se ha llevado a cabo un análisis cuantitativo-cualitativo basado en corpus. El objetivo de este análisis es, por un lado, determinar el número y tipología (rasgos morfosintácticos) de las etiquetas empleadas en estas cuentas, por otro, identificar sus principales funciones discursivas en el contexto del microblog. Por último, se busca establecer las semejanzas y diferencias que presentan las etiquetas en función de las tres cuentas, con la intención de ver qué papel ha jugado este dispositivo en el discurso público institucional sobre la crisis pandémica.

Como se recoge en la Tabla 1, el corpus está constituido por 9000 tuits, recopilados automáticamente mediante el programa ExportComments a través del sistema de extracción por perfiles: @desdelamoncloa,@sanidadgoby @@SaludPublicaEs. Se han extraído 3000 tuits publicados en cada una de esas cuentas durante un año, desde el 15 de mayo de 2020 hasta el 15 de mayo de 2021. Del corpus se han excluido los retuits o reenvíos de mensajes de otros usuarios, así como las respuestas recibidas en la cronología en Twitter de estas tres cuentas oficiales del gobierno:

\begin{tabular}{|l|l|l|l|}
\hline Perfiles & Tuits & N. total hashtags & N. total hashtags Covid-19 \\
\hline @desdelamoncloa & 3000 & 3360 & $936(27,85 \%)$ \\
\hline @sanidadgob & 3000 & 4320 & $1642(38 \%)$ \\
\hline @SaludPublicaEs & 3000 & 4901 & $2143(43,72 \%)$ \\
\hline TOTAL & $\mathbf{9 0 0 0}$ & $\mathbf{1 2 . 5 8 1}$ & $\mathbf{4 7 2 1}(\mathbf{3 7 , 5 2} \%)$ \\
\hline
\end{tabular}

Tabla 1. Tuits recopilados, $\mathrm{n}$. de hashtags totales y n. de hahstags relacionados con la Covid-19. 
Como es posible observar, el dato relativo al número de hashtags totales empleados en las tres cuentas indica que prácticamente todos tuits publicados contienen al menos uno, por lo que su uso, durante el periodo seleccionado, ha sido habitual en los tres perfiles, en especial, en el del ministerio de Sanidad y en el de Salud pública. Cabe precisar que no existe una correspondencia exacta entre el número de tuits publicados y número de etiquetas empleadas: por una parte, no todos los mensajes contienen este dispositivo, por otra, es muy frecuente que en un mismo texto aparezcan varias etiquetas.

A partir de estos datos, se ha llevado a cabo un análisis semiautomatizado con Sketch Engine (funciones wordlist y concordance) de las etiquetas relativas a la gestión de la pandemia, relacionadas con la Covid-19, las campañas de prevención de contagios, de vacunación, las ruedas de prensa dedicadas a comunicar las medidas, etc. La función wordlist permite obtener la frecuencia de palabras por categoría gramatical; también permite identificar rápidamente las formas fusionadas que aparecen en el corpus, además de su frecuencia. Mediante la función concordance, es posible analizar cada forma encontrada en el cotexto inmediato, esto es, en relación con los elementos lingüísticos con los que coaparece en un tuit.

Los datos de la tercera columna (Tabla 1) indican que los hashtags relacionados con la gestión de la crisis constituyen un 37,52 \% del total. Por perfiles, notamos que los de @SaludPublicaEs son poco menos de la mitad (43,72\%), seguidos de los que aparecen en los mensajes de @sanidadgob (38\%) y, a mayor distancia, de los que publica@desdelamoncloa (27,85\%). El dato no sorprende si se tiene en cuenta el papel y función que tienen cada uno de estos perfiles: frente al del gobierno, dedicado a informar sobre las medidas adoptadas en todos los ámbitos de la administración pública y especialmente, durante estos meses, sobre las políticas aprobadas para hacer frente a los problemas económicos y sociales derivados de la crisis pandémica, los mensajes del ministerio de Sanidad y, en particular, la cuenta de Salud pública, se centran en informar a la ciudadanía sobre las medidas de prevención y contención de la enfermedad.

\section{RESULTADOS}

\subsection{Análisis cuantitativo}

Como se apuntaba, en el corpus de tuits recogidos para este estudio se han empleado un total de 4721 etiquetas relacionadas con la Covid-19. Sin embargo, solo $210(4,36 \%)$ son únicas o no repetidas. Si se consideran las ocurrencias de hashtags no repetidos respecto al número total (v. Tabla 2), notamos una frecuencia de uso similar en los tres perfiles: 


\begin{tabular}{|l|l|l|}
\hline Perfiles & N. total hashtags Covid-19 & $\begin{array}{l}\text { N. hashtags Covid-19 únicos } \\
\text { (no repetidos) }\end{array}$ \\
\hline @desdelamoncloa & 936 & $49(5,23 \%)$ \\
\hline @sanidadgob & 1642 & $67(4,08 \%)$ \\
\hline @SaludPublicaEs & 2143 & $90(4,19 \%)$ \\
\hline TOTAL & $\mathbf{4 7 2 1}$ & $\mathbf{2 0 6}(4,36 \%)$ \\
\hline
\end{tabular}

Tabla 2. N. de hashtags totales y únicos (no repetidos) sobre la Covid-19.

Tomando en cuenta este último dato (206 únicos), se ha llevado a cabo un análisis de frecuencia por tipología, de acuerdo con la taxonomía propuesta en Mancera Rueda y Pano Alamán (2015) para el análisis de los rasgos lingüísticos (morfosintácticos) de la etiqueta en el discurso político. Esta primera clasificación ha permitido obtener los porcentajes de las que están formadas por una única palabra (lema), una secuencia de palabras (e.g. un sintagma o una oración), una sigla o una secuencia alfanumérica. La Figura 1 presenta el porcentaje de etiquetas por perfil y por tipología:

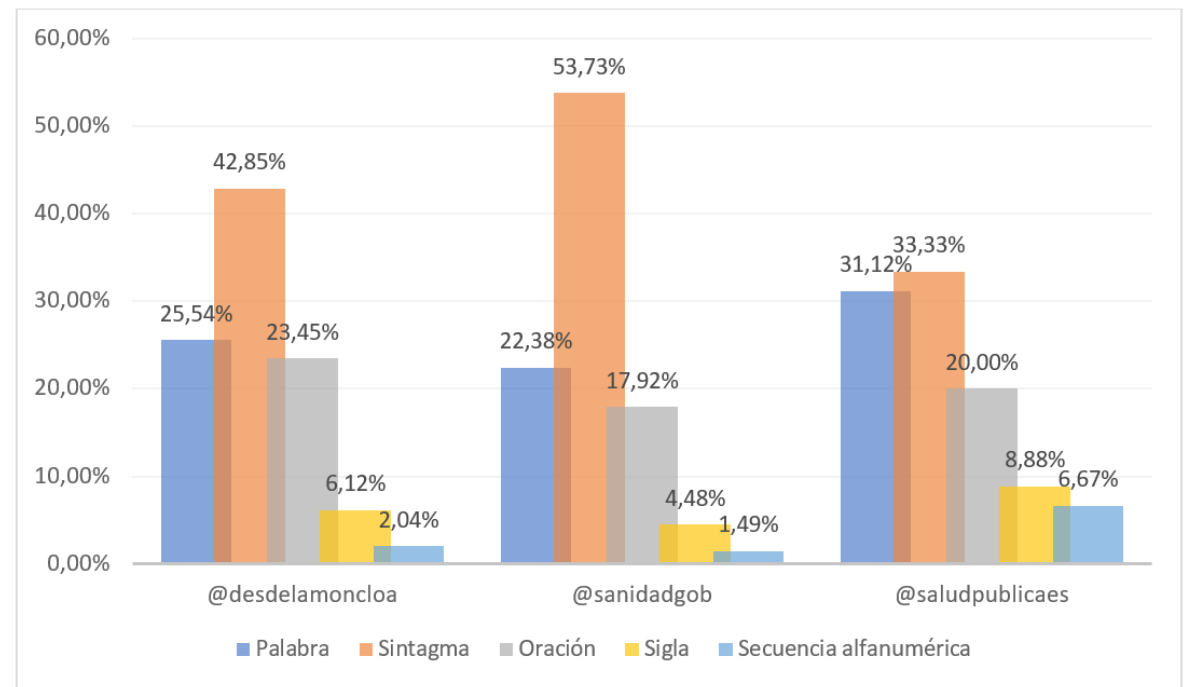

Fig. 1. Porcentaje ponderado de hashtags totales y únicos (no repetidos) por perfil.

Cabe señalar, de entrada, que la mayor parte de los hashtags empleados en las tres cuentas son sintagmas, cuyas lexías aparecen fusionadas; esto es más evidente en la cuenta de @sanidadgob, en la que poco más de la mitad de las etiquetas 
utilizadas (53,73\%) presenta estructuras como \#VacunasCovid, \#elretodetodos o \# radarcovid. Los porcentajes de uso son similares respecto a las etiquetas formadas por un único lema, aunque estas presentan mayor frecuencia en la cuenta de @SaludPublicaEs $(31,12 \%)$. Algunos ejemplos de este tipo son \#mascarilla* \# \#acuna* o \#desescalada. Las que están constituidas por oraciones, esto es, las que contienen un sintagma verbal, como son \#YoMeVacunoSeguro o \#ElMejorRegaloEsCuidarnos, son en cambio más frecuentes en los mensajes de @desdelamoncloa (23,45\%), aunque su presencia es significativa también en los tuits de los otros dos perfiles. Diverso es el caso de las que están formadas por siglas (\#CCAA, \#SNS, \#PCR) o por secuencias alfanuméricas (\#6M, \#Fase3), pues son más frecuentes en los tuits de @SaludPublicaEs ( $8,88 \%$ y 6,67 \%, respectivamente). Desde el punto de vista de los rasgos morfosintácticos, los datos señalan un empleo más diversificado de las etiquetas en este último perfil, mientras que en los otros dos predominan los sintagmas, las palabras y las oraciones, frente a las siglas y las secuencias alfanuméricas.

En los párrafos que siguen nos centramos en el contenido de las más frecuentes. La Tabla 3 recoge las que presentan un número de ocurrencias mayor o igual a 15, distribuidas por perfil:

\begin{tabular}{|c|c|}
\hline Perfiles & Etiquetas más frecuentes ( $\geq 15$ ocurrencias) \\
\hline @desdelamoncloa & $\begin{array}{l}\text { \#Covid19 (409); \#YoMeVacuno (140); \#VacunaCovid1(84); } \\
\text { \#PlanEspañaPuede (71); \#YoMeVacunoSeguro (33); } \\
\text { \#ElMejorRegaloEsCuidarnos (23); \#VacunasCovid (19); } \\
\text { \#AppRadarCovid (17); \#EspañaPuede (15) }\end{array}$ \\
\hline @sanidadgob & $\begin{array}{l}\text { \#YoMeVacuno (339); \#VacunaCovid19 (131); \#QuédateEnCasa } \\
\text { (104); \#Coronavirus (90); \#Vacunación (88); \#YoMeVacunoSeguro } \\
\text { (86); \#AppRadarCovid (74); \#directorueda (73); } \\
\text { \#ElMejorRegaloEsCuidarnos (59); \#SNS (50); \#EstoNoEsUnJuego } \\
\text { (41); \#VacunaCovid (32); \#mascarilla* (31); \#vacuna* (29); \#6M (27); } \\
\text { \#NoLoTiresPorLaBorda (24); \#AstraZeneca (18); \#ENECovid (16); } \\
\text { \#RecuerdosInolvidables (15); \#endirecto (15); \#RadarCovid (15) }\end{array}$ \\
\hline @SaludPublicaEs & $\begin{array}{l}\text { \#NoLoTiresPorLaBorda (440); \#YoMeVacuno (246); } \\
\text { \#EsteVirusLoParamosUnidos (132); \#EstoNoEsUnJuego (128); } \\
\text { \#VacunaCovid19 (104); \#mascarilla* (93); \#directorueda } \\
\text { (88); \#AppRadarCovid (63); \#QuédateEnCasa (60); } \\
\text { \#ElMejorRegaloEsCuidarnos (59); \#YoMeVacunoSeguro (54); } \\
\text { \#6M (51); \#coronavirus (43); \#VacunaCovid (37); \#CCAA (35); } \\
\text { \#desescalada (33); \#CreaTuBurbuja (33); \#RecuerdosInolvidables } \\
\text { (29); \#Fase2 (25); \#RadarCovid (25); \#NuevaNormalidad (17); } \\
\text { \#NoLoTiresPorLaBordaMás (17); \#PCR (16); \#Fase3 (15); \#Fase1 (15) }\end{array}$ \\
\hline
\end{tabular}

Tabla 3. Etiquetas más frecuentes por perfil (n. ocurrencias). 
Como se puede observar, algunas de estas etiquetas aparecen en los mensajes de las tres cuentas, muestra de que se ha adoptado una misma estrategia comunicativa en Twitter. Véase, por ejemplo, el caso de \#YoMeVacuno o \#appradarcovid, que hacen referencia a dos de las medidas adoptadas por el gobierno: la creación de la app Radar Covid para el rastreo de contagios y la campaña de vacunación, cuya primera fase se sitúa entre enero y febrero de 2021. De hecho, la mayor parte de los hashtags hace referencia a las vacunas, véase, por ejemplo, el número de ocurrencias de \#YoMeVacuno en el corpus global (725), que constituye un 15,35\% del total de etiquetas relacionadas con la Covid-19 en el corpus.

Atendiendo a la frecuencia de empleo por perfiles, cabe notar algunos aspectos diferenciados. En primer lugar, en la cuenta de Moncloa predomina el genérico \#Covid19 (409 ocurrencias, 43,69 \%), que alude a la enfermedad por coronavirus, seguido de los que hacen referencia a la campaña de vacunación (\#YoMeVacuno, \#VacunaCovid 19, \#YoMeVacunoSeguro, \#VacunasCovid), con 276 ocurrencias totales, lo cual permite afirmar que los mensajes publicados en este perfil durante el periodo considerado se centran en el tema de la vacunación. Si bien, cabe señalar que de las 188 ocurrencias de "vacuna" que aparecen en los tuits de @desdelamoncloa, solo una funciona como etiqueta. En los publicados en el perfil del gobierno destacan también \#PlanEspañaPuede y \#EspañaPuede (86 ocurrencias), que remiten al "Plan de Recuperación, Transformación y Resiliencia" o "Plan España Puede", aprobado por el Consejo de Ministros del pasado 27 de abril de 2021. En este caso, se insiste sobre el plan de recuperación y sobre las políticas que el gobierno adopta para dar respuesta a la crisis económica y social, un tema tratado únicamente en los tuits de este perfil, siendo mucho menor su presencia ( 9 ocurrencias de \#EspañaPuede) en los mensajes de@sanidadgob.

Las etiquetas que se emplean en las otras dos cuentas institucionales presentan más semejanzas. Las más frecuentes son las que están directamente relacionadas con la vacunación de la población, por ejemplo: las estructuras oracionales \#YoMeVacuno y \#YoMeVacunoSeguro, que suman 425 ocurrencias en el subcorpus de @ sanidadgob y 300 en el de @SaludPublicaEs; el tipo de vacunas, como las relativas al nombre genérico de la vacuna, \#VacunaCovid19 y \#VacunaCovid (163 y 123, respectivamente, en los tuits de Sanidad y en los de Salud Pública) o las referidas al nombre específico de una de ellas, \#AstraZeneca (18 en el subcorpus de @sanidadgob); y los lemas \#vacunación y \#vacuna* (117 en @sanidadgob y 37 en @ SaludPúblicaEs).

También son frecuentes en estos dos perfiles \#directorueda y \#endirecto (con un total de 211 ocurrencias en los tuits de @sanidadgob), cuya función es la de anunciar la rueda de prensa o la comparecencia en directo de uno de los portavoces 
del gobierno, además de contextualizar lo que se dice en esa determinada situación enunciativa; los mensajes en que aparecen se hacen eco de las palabras del presidente del gobierno, del ministro de sanidad o del portavoz cuando informan sobre nuevos datos (contagios, vacunas) o nuevas medidas, e incluyen generalmente el vídeo que, desde Twitter, emite en directo.

Otras etiquetas frecuentes en los tuits de estos dos perfiles son las que se refieren a las medidas de contención del contagio, como \#mascarilla* 335 ocurrencias totales en los subcorpus@sanidadgob y @SaludPublicaEs), el predicado en imperativo \#quédateencasa (164), y el sintagma mencionado \#appradarcovid o \#radarcovid (177). Destacan asimismo los hashtags que se apoyan en un predicado nominal o verbal como \#ElMejorRegaloEsCuidarnos, empleado también en los tuits de @ desdelamoncloa (141), \#EstoNoEsUnJuego (169) o \#NoLoTiresPorLaBorda (464), que es la más frecuente en el subcorpus de @SaludPublicaEs. Su función parece ser la de promover un determinado comportamiento entre los usuarios de la red, pues se relacionan directamente con el título de algunas de las campañas lanzadas desde el gobierno para sensibilizar a la población. Asimismo, las últimas dos cuentas presentan un empleo similar de hashtags como las siglas \#SNS, Sistema Sanitario de Salud; la combinación de siglas y lema, como \#ENECovid, que alude al "Estudio Nacional de sero-Epidemiología de la infección por SARS-CoV-2 en España”, disponible en la web del Centro Nacional de Epidemiología; y la secuencia \#6M, etiqueta creada en el ámbito de la campaña "El mejor regalo es cuidarnos", que fue lanzada en diciembre de 2020 con el objeto de recordar a la ciudadanía la necesidad de respetar, durante las fiestas de Navidad, las 6 medidas que hasta entonces habrían permitido evitar el mayor número de contagios. La etiqueta sintetiza, pues, las seis recomendaciones que inician con la "m": Mascarilla, Metros, Manos, Menos contactos, Más ventilación y Me quedo en casa. Por último, cabe destacar que, contrariamente a lo observado en investigaciones sobre el empleo de hashtags en el discurso de las fuerzas de seguridad, de ayuntamientos o de los partidos políticos en Twitter, los que indican un lugar o una fecha específicos tienen en este corpus una presencia menor. Aparecen únicamente en los tuis de @SaludPublicaEs, donde \#aeropuerto, \#8M2021, \#DíaDelPadre y \#Mérida presentan una única ocurrencia.

\subsection{Análisis cualitativo}

A través de las concordancias obtenidas, en este apartado se analiza el comportamiento sintáctico y semántico de las etiquetas más frecuentes (v. Tabla 3), así como la función discursiva del enunciado en que aparecen. En este caso, se intenta determinar si se trata de etiquetas empleadas en el contexto del tuit con función 
informativa, argumentativa o persuasiva.

Las etiquetas más frecuentes en los mensajes de los tres perfiles son las que, como \#VacunaCovid o \#VacunaCovid19, están compuestas por sintagmas. Estas suelen integrarse en estructuras oracionales con funciones de sujeto (1) o complemento de nombre (2):

(1)@desdelamoncloa: Las/la \#VacunaCovid19 que se emplearán para inmunizar a la población dispondrán de los mismos niveles de seguridad que cualquiera de las que se emplean habitualmente.Los niveles de eficacia cumplirán con los estándares exigidos para que su uso sea autorizado (https://twitter.com/desdelamoncloa/status/1331224125851963404, 24-11-2020).

(2)@SaludPublicaEs: Esta semana han llegado a España un total de 1.066.350 dosis de \#VacunaCovid19, para su distribución entre las comunidades autónomas: 393.600 nuevas dosis de la vacuna Moderna 672.750 nuevas dosis de la vacuna Pfizer \#YoMeVacuno (https://twitter. com/saludpublicaes/status/1377993723594805250, 02-04-2021).

En el primer ejemplo, el hashtag se inserta en un enunciado con función argumentativa a través del cual se afirma que esta vacuna es segura como "cualquiera de las que se emplean habitualmente"; en el segundo, el enunciado en que aparece es informativo, pues anuncia la llegada de un alto número de dosis de esa vacuna. No obstante, el hecho de que se proporcionen cifras de cada tipo de vacuna y se incluya al final del mensaje \#YoMeVacuno, acto declarativo que, a través del yo inclusivo invita al destinatario del mensaje a identificarse con el locutor, lleva a inferir que la vacuna está al alcance de todos. En ese contexto, ambas etiquetas parecen estar también al servicio de la persuasión, en un tuit que busca convencer de la eficaz distribución de las vacunas. Se trata, en este casos, de un hashtag final, cuyo contenido guía el proceso inferencial del lector para interpretar ese enunciado (Scott, 2015: 13).

Otras resumen el contenido del mensaje, a modo de palabra clave con función informativa y tematizadora. Por ejemplo, en (3), \#VacunaCovid aparece al final del tuit desvinculada de las estructuras oracionales que conforman el enunciado informativo con el que se anuncia la publicación de los datos intermedios de BioNTech y Pfizer sobre la eficacia de su vacuna. El hashtag, que alude de forma genérica a la vacuna contra la Covid, constituye un enunciado independiente, cuya función es informativa y tematizadora, pues se puede considerar como una palabra clave que resume el contenido o el tema principal del mensaje (Bani, 2020: 80). Además, en 
el contexto del microblog, al ser un enlace, permite a quien esté interesado en informarse sobre la evolución de la vacuna, rastrear todos los tuits relacionados con ese mismo tema:

(3) @sanidadgob: BioNTech y Pfizer publican datos intermedios de eficacia de su vacuna contra la \#Covid 19 Los datos preliminares del ensayo clínico en fase III, todavía en curso, resultan prometedores con un $90 \%$ de eficacia vacunal. Más información: https://t.co/JvZxYGJUVY \#VacunaCovid (https://twitter.com/sanidadgob/status/1326210644505407489, 10-11-2021).

De forma similar a las que se han comentado en (1) y (2), las etiquetas constituidas por un solo lema, como \#coronavirus, \#vacunación, \#mascarilla*, \#vacuna*, \#desescalada o \#AstraZeneca, suelen integrarse en estructuras oracionales con funciones sintácticas específicas. Por ejemplo, \#coronavirus en (4) se inserta dentro de una oración con la función de sujeto. Este comportamiento se observa también en otros mensajes, en los que el virus parece personalizarse: "el \#coronavirus sigue ahí". El enunciado en el que aparece introduce así el argumento que justifica el acto directivo previo, por el cual se exhorta al potencial lector del tuit a no bajar la guardia y a adoptar "tus principales armas" contra el virus:

(4) @sanidadgob: ¡No bajes la guardia en ningún momento! Recuerda que aunque no se vea el \#coronavirus sigue ahí. Mascarilla, higiene de manos, distancia, ventilación y @AppRadarCovid son tus principales armas. ¡Úsalas! \#ElMejorRegaloEsCuidarnos https://t.co/uJsFmSXkfa [enlace a video en TikTok] (https://twitter.com/sanidadgob/status/1346008970423623685, 0401-2021).

Pero este tipo de etiquetas suelen incluirse también en los mensajes de todos los perfiles dentro de estructuras como "datos de \#covid" (5), con función esencialmente informativa:

(5)@Sanidadgob: Actualización de datos de \#Covid 19https://t.co/ tffgEzvjZk Infografías y otros materiales sobre el \#coronavirus https://t.co/dzocoyr8qR [enlace a sitio web de ministerios de Sanidad, Derechos sociales y Consumo] (https://twitter.com/sanidadgob/status/1341065958006374402, 21-12-2020). 
Desde un punto de vista sintáctico, las etiquetas compuestas por sustantivos o sintagmas nominales y que no aluden directamente al virus o a la vacuna, se comportan de forma similar a las precedentes, aunque en estos casos pueden pasar desapercibidas en el tuit, por lo que requieren un mayor esfuerzo interpretativo a partir del significado que adquieren en su contexto lingüístico y de los supuestos contextuales que activan. Véase en (6) \#desescalada, cuyo significado es según el Diccionario de la lengua española: "1. f. Descenso o disminución graduales en la extensión, intensidad o magnitud de una situación crítica, o de las medidas para combatirla" (DLE, ed. 23.4, 2020):

(6)@SaludPublicaEs: Seguimos progresando en la \#desescalada Se ha reducido el número de contagios Podemos ir avanzando hacia la \#NuevaNormalidad. Sigamos siendo RESPONSABLES \#NoLoTiresPorLaBorda MUCHAS GRACIAS \#EsteVirusLoParamosUnidos (https://twitter. com/SaludPublicaEs/status/1270777750190727171, 10-06-2020).

La palabra se integra en la primera oración dentro de un enunciado que celebra en cierta manera el hecho de que el país siga progresando en la diminución de las primeras medidas adoptadas para combatir la pandemia; el mensaje es de junio de 2020, cuando se iniciaba la fase 3 o "fase avanzada" por la que se reducían las restricciones a la movilidad de las personas. Este enunciado va introducido por un emoji que imita el aplauso y que se inserta al inicio de cada oración, a modo de aprobación y celebración. De hecho, junto a \#desescalada, se emplea otro hashtag, \#NuevaNormalidad, que hace referencia a otro de los términos clave lanzados desde las instituciones para caracterizar esta fase de gestión de la pandemia. El empleo de verbos como "progresar" y "avanzar" en la misma estructura en la que se utilizan estas dos etiquetas, las dota de significado positivo; asimismo, en ese contexto, en el que se inserta otro enunciado sobre el descenso del número de contagios, invitan a inferir que el gobierno y los ciudadanos (véase el empleo del nosotros inclusivo) están entrando en una nueva fase libre del virus. Se trata asimismo de enunciados argumentativos, mediante los cuales Salud Pública busca convencer a los ciudadanos que leen ese mensaje en Twitter de la necesidad de seguir siendo responsables y no bajar la guardia. Como se observa, las mayúsculas en "responsables" y el hashtag que sigue (\#NoLoTiresPorLaBorda) y que vehicula otro acto directivo, redundan en esta misma idea. El mensaje se cierra con la etiqueta \#EsteVirusLoParamosUnidos, predicado verbal que retoma, como se apuntaba, el título de una de las campañas del gobierno para hacer frente a la crisis. Se trata de un acto declarativo, que incide en la importancia de la unidad y, por tanto, el esfuerzo de todos, para "parar" el virus. 
Buena parte de las etiquetas del corpus se apoya en predicados como: \#YoMeVacuno, \#YoMeVacunoSeguro, \#ElMejorRegaloEsCuidarnos, \#QuédateEnCasa, \#EstoNoEsUnJuego, \#NoLoTiresPorLaBorda, \#NoLoTiresPorLaBordaMás y \#CreaTuBurbuja, si bien estas dos últimas aparecen solamente en el subcorpus de @ SaludPublicaEs. Destacan, pues, dos tipos de predicados: verbales, con verbos como "vacunar", "quedarse", "tirar" o "crear" y nominales con "ser". Por otro lado, algunas etiquetas incluyen el pronombre de primera persona singular $(y o)$ o el clítico de primera plural (nos), con valor inclusivo en este tipo de mensajes; otras emplean las formas de segunda persona singular (clítico te, posesivo tu) para dirigirse al usuario de Twitter y, en definitiva, al ciudadano, expresando cercanía. Igualmente, presentan un significado más complejo y requieren un esfuerzo interpretativo mayor en base al contexto de la pandemia, relacionado con lo que los usuarios saben acerca de las políticas adoptadas por el gobierno para afrontar la crisis y que pueden hacer referencia a las campañas del gobierno, como en el caso de \#EsteVirusLoParamosUnidos (6), a las medidas de contención, a la campaña de vacunación y a los comportamientos que se busca inculcar en la ciudadanía.

Las que presentan más ocurrencias en los subcorpus de @desdelamoncloa y @ sanidadgob son \#YoMeVacuno y \#YoMeVacunoSeguro, mientras que en el de @SaludPublicaEs, predomina \#NoLoTiresPorLaBorda. Las dos primeras suelen aparecer en el cierre del tuit, especialmente, en los mensajes de Moncloa, donde se coloca también separado del resto del texto con el objetivo de tematizar el mensaje, como veíamos en (2), y agrupar los mensajes relacionados con el plan de vacunación que se publican en Twitter:

(7)@desdelamoncloa: El ministro de @sanidadgob explica que el objetivo en materia de vacunación es que a finales de esta semana todas las residencias de mayores hayan recibido la primera dosis de la \#vacunaCovid19. Se prevé que en estos días la vacunación alcance velocidad de crucero. \#YoMeVacuno (https://twitter.com/desdelamoncloa/status/1348997157945163777, 12-01-2021).

(8)@Sanidadgob: El proceso de \#vacunación en España va a buen ritmo España se sitúa entre los primeros países del mundo en dosis administradas La estrategia acordada con las CC.AA funciona Un único plan, un plan para todos y todas \#YoMeVacuno (https://twitter.com/sanidadgob/status/1352323436245348352, 2101-2021). 
De este modo, dota de mayor visibilidad el contenido del mensaje además de permitir que los usuarios puedan buscar mensajes similares publicados en el microblog. En los ejemplos anteriores, las etiquetas vienen precedidas de enunciados que informan desde una perspectiva optimista del buen ritmo de la campaña de vacunación, véase "que la vacunación alcance velocidad de crucero" (7) y la más explícita "el proceso [...] va a buen ritmo" (8). Se trata de argumentos que permiten al gobierno afirmar que su estrategia funciona; de hecho, en los tuits de @SaludPublicaEs se han encontrado 5 ocurrencias de la etiqueta \#LasVacunasFuncionan. El objetivo del mensaje institucional, sintetizado en la fórmula final \#YoMeVacuno, es la de convencer a los usuarios de Twitter que leen ese mensaje de que el plan de vacunación es eficaz y de que su implementación sigue un buen ritmo, dando respuesta así a los contradiscursos que circulaban en las redes y en algunos medios sobre la supuesta tardanza en distribuir las dosis. Veamos otros casos similares:

(9) @Sanidadgob: Hoy se distribuyen entre las \#CCAA más de 1.700 .000 nuevas dosis de la \#VacunaCovid19 de \#Pfizer/BioNTech \#YoMeVacuno \#YoMeVacunoSeguro (https://twitter.com/sanidadgob/status/1399266899066724363, 10-05-2021).

(10)@SaludPublicaEs: La efectividad de la vacunación contra el \#COVID19 entre los residentes en centros de mayores se sitúa entre el $81 \%$ y el $88 \%$ La vacunación ha evitado un $71 \%$ de las hospitalizaciones y un $82 \%$ de los fallecimientos Más https://t.co/Ya1Lf5y6Gy \#YoMeVacuno \#YoMeVacunoSeguro (https://twitter.com/SaludPublicaEs/status/1390609854826303490, 07-05-2021).

Como se puede notar, en posición final de estos mensajes, aparecen dos hashtags con estructura sintáctica y significado aparentemente similares: emplean el mismo verbo y el yo con el que se pretende que el ciudadano se identifique. Sin embargo, el adjetivo "seguro" que se añade en la segunda etiqueta aporta un nuevo matiz al significado de ese predicado, que pasa por las múltiples acepciones que tiene el adjetivo: "1. adj. Libre y exento de riesgo; 2 . adj. Cierto, indubitable; 4. adj. Que no falla o que ofrece confianza; 5. adj. Dicho de una persona: Que no siente duda. Está segura de ello" (DLE, 23.4, 2020). Así, el adjetivo puede adquirir distintos sentidos en ese contexto, asociados al acto de vacunarse -nótese que el presente de indicativo empleado puede expresar también una acción futura-. Por ejemplo, el interlocutor puede interpretar que vacunarse es una acción exenta de riesgo, o que no falla; o bien que se llevará a cabo de forma cierta; o incluso que quien se vacuna $(y o)$, lo hace sin 
dudar. Ante el clima de desconfianza, escepticismo y miedo que las vacunas o algunas de ellas han generado en los últimos meses, y para evitar la circulación de bulos, esta etiqueta y los enunciados argumentativos con los que coaparece en el mismo mensaje, buscan convencer a la ciudadanía de que la vacuna funciona y es segura.

En lo que respecta a las etiquetas donde se emplea un verbo en imperativo, como \#QuédateEnCasa o \#NoLoTiresPorLaBorda, cabe recordar su uso preferencial en los tuits del ministerio de Sanidad y en los de Salud Pública. Su función en estos mensajes es esencialmente persuasiva, pues inducen a hacer algo mediante argumentos razonados. Como podemos observar en (11), el hashtag que introduce el mensaje insta a quedarse en casa si se dan una serie de condiciones. El mensaje contiene distintos elementos lingüísticos, como las condicionales, y semióticos, como los símbolos con distinta forma y color, que guían al destinatario en la interpretación de los supuestos en los que debe guardar cuarentena:

(11) @Sanidadgob: \#QuédateEnCasa si: Tienes síntomas de \#Covid19 Has sido diagnosticado como positivo https://t.co/QVPYAIngoa Has tenido un contacto estrecho con una persona diagnosticada de Covid-19 https://t.co/IY0Uole1Ql [enlace a documento en pdf del ministerio sobre la cuarentena] (https://twitter.com/sanidadgob/status/1330800370340212737, 23-11-2020).

(12)@SaludPublicaEs: Reduce el número de contactos para evitar contagios y detener la propagación del \#Covid19. Mascarilla, distancia, lavado de manos y, si tienes síntomas, \#QuédateEnCasa. \#CreaTuBurbuja y no salgas de ella $;$ Con tu ayuda saldremos de esta! (https://twitter.com/saludpublicaes/status/1353720531867074561, 14-11-2020).

Nótese, en cambio, la acumulación de actos directivos en (12), donde, además de \#QuédateEnCasa, se emplea \#CreaTuBurbuja, hashtag más creativo, que invita de forma original a aislarse en caso de presentar síntomas. Esta etiqueta hace referencia a la campaña que se lanzó desde el gobierno y varias CCAA, para convencer a la población de la necesidad de reducir los contactos y mantener las medidas de prevención. Como se puede observar en la Figura 2, en algunos de los mensajes que contenían la etiqueta se emplearon diversos emojis y vídeos, especialmente dirigidos a la población más joven: 


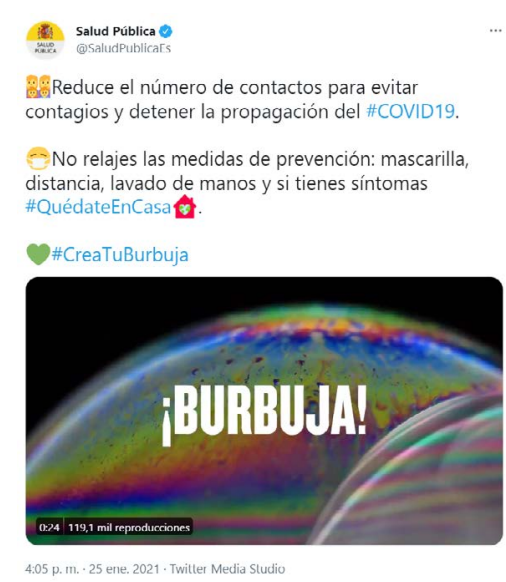

Fig. 2. Tuit de@SaludPublicaEs (https://twitter.com/saludpublicaes/ status/1353720531867074561).

Este - como \#NoLoTiresPorLaBorda, que se apoya en la conocida locución verbal- es un hashtag original en el que se emplea la metáfora de la burbuja. Sin embargo, en este contexto, la metáfora puede ser ambigua, al hacer referencia a un espacio etéreo y agradable, cuando en realidad se utiliza con el sentido de aislarse en casa, algo que, a un año del inicio de la pandemia, empezaba a percibirse quizá de forma más negativa. Los argumentos y dispositivos multimodales que se incluyen en los tuits buscan aclarar el sentido de ese acto directivo y vehicular un mensaje que invita a interpretar de forma positiva lo que parece una orden como una nueva posibilidad, la de crearse un espacio libre de contagios.

En este sentido merece la pena mencionar el sintagma \#RecuerdosInolvidables, que se utiliza en los mensajes del ministerio de Sanidad y en los de Salud Pública en 44 ocasiones. Se trata de una etiqueta insertada en mensajes relacionados con el reciclaje de las mascarillas, el hidrogel y los guantes, que empezaron a usarse masivamente desde el inicio de la pandemia para protegerse de los contagios. Debido a su uso extendido entre la población y a la dificultad de reciclar este tipo de materiales, los ministerios para la Transición Ecológica y el Reto Demográfico y el de Consumo lanzaron la campaña "Recuerdos inolvidables. La mascarilla es para ti, no para la naturaleza”, con el objetivo de promover el uso de mascarillas protectoras y sensibilizar a los ciudadanos sobre los efectos del abandono de estos residuos higiénico-sanitarios en entornos naturales. Los perfiles en Twitter de Sanidad y Salud Pública se hicieron eco de la campaña a través de mensajes como los que siguen: 
(13) @sanidadgob: Recuerda. La mascarilla, el hidrogel, los guantes... son para ti, no para la naturaleza Una mascarilla tarda entre 300 y 400 años en desaparecer Tira tus residuos siempre en el contenedor de restos y evita dejar en el paisaje \#RecuerdosInolvidables \#Covid19 (https://twitter. com/sanidadgob/status/1371078155008610305, 14-03-2021).

(14)@SaludPublicaEs: Los residuos relacionados con la pandemia de \#Covid19 tardan siglos en desaparecer abandonados en la naturaleza: na \#mascarilla higiénica entre 300 y 400 años Tíralas siempre en el contenedor de restos, evita dejar en el paisaje \#RecuerdosInolvidables (https://twitter.com/saludpublicaes/status/1357318992516452357, 04-02-2021).

El hashtag, que retoma parte del título de la campaña, se inserta en ambos casos como objeto directo en la estructura sintáctica de la última oración, en el predicado "evita dejar en el paisaje \#RecuerdosInolvidables". Este acto directivo invita a reciclar la mascarilla en un contenedor específico, tras indicar las razones por las que es necesario hacerlo. No obstante, el significado de la etiqueta puede ser ambiguo, en la medida en que el sintagma "recuerdos inolvidables" puede evocar en la mente del destinatario un recuerdo que no puede olvidarse, un recuerdo agradable. En este sentido, el dispositivo no es transparente, pues, a primera vista, resulta más difícil inferir que se trata de un residuo, y no de un recuerdo, que en el caso de no reciclarse será imposible olvidar. $\mathrm{Al}$ sentido positivo que suele asignarse a la colocación "recuerdo inolvidable" se le da un sentido más negativo, conectado con la amenaza y el riesgo de que esos productos contaminen la naturaleza. El cotexto es aquí esencial para interpretar correctamente su sentido, si bien en este entorno no es posible controlar cuándo o quién leerá un mensaje ni es posible predecir qué supuestos contextuales serán accesibles para los lectores potenciales en el momento del procesamiento (Scott, 2015). La inclusión de hashtags originales en sus mensajes permite a las instituciones captar la atención de los usuarios en la red social y trasmitir sus mensajes de forma creativa, de manera que los destinatarios no se acostumbren a las mismas fórmulas. Sin embargo, es importante colocarlos en un enunciado claro que dé acceso a los supuestos que se busca activar, puesto que, como se ha señalado, la comunicación institucional de crisis debe ser clara y transparente, además de mantener el canal abierto con el ciudadano.

Las etiquetas del corpus que contienen un predicado nominal se relacionan en todos los casos con las campañas lanzadas por el gobierno, de modo que es posible considerarlas como consignas: \#ElMejorRegaloEsCuidarnos y \#EstoNoEsUnJuego. El contexto lingüístico, en el que abundan los enunciados con función exhortativa, permiten captar el sentido del hashtag. Por ejemplo, en (15), se infiere que el mejor 
regalo de Navidad es el de cuidarse y cuidar a quienes se tiene cerca, implicando así que el deber de todos es seguir las recomendaciones de la nueva guía publicada por el gobierno:

(15)@desdelamoncloa: En estas fechas, respeta las indicaciones de las autoridades sanitarias, porque \#ElMejorRegaloEsCuidarnos. Si vas a acudir a alguna estación de esquí o montaña, sigue las recomendaciones específicas frente al \#Covid19 de la nueva guía de @mincoturgob (https://twitter.com/desdelamoncloa/status/1339996600941178880, 18-12-2020).

(16) @sanidadgob: Haciendo un uso correcto de la mascarilla te proteges y proteges a los demás Recuerda: si llevas la mascarilla en la barbilla estás desprotegid@ frente a la \#Covid19 Cúbrete la boca, la nariz y barbilla y ajústate bien la mascarilla \#NoLoTiresPorLaBorda \#EstoNoEsUnJuego (https:// twitter.com/sanidadgob/status/1310219894630342657, 23-09-2021).

En (16), el tono parece más perentorio, nótese el uso consecutivo de dos hashtags que se apoyan en enunciados exhortativos negativos; el primero retoma de nuevo el título de la campaña lanzada por el ministerio de Sanidad en agosto de 2020, para convencer a los ciudadanos a mantener las medidas de seguridad; el segundo coincide con el lema de otra campaña mediante la cual se insistía en seguir las recomendaciones sanitarias. En este caso, se insiste vehementemente sobre la gravedad de las consecuencias de contraer la enfermedad ("no es un juego"), en un momento a inicios de otoño de 2020 en el que los datos sobre los nuevos contagios empezaban a preocupar a las autoridades.

Como se decía, la presencia de etiquetas con siglas es poco significativa y se limita a pocas ocurrencias en los perfiles del ministerio de Sanidad y de Salud Pública: \#SNS, \#6M, \#Fase2, \#PCR, \#Fase3, \#Fase1. En (17), la secuencia contribuye a sintetizar las recomendaciones para evitar contagios, mientras que en (18) la sigla alude al término técnico relativo a las pruebas de diagnóstico del coronavirus (PCR), que la ciudadanía ya conocía y que en este mensaje se repiten para aclarar el tipo de prueba que se ha realizado a millones de personas:

(17)@saludPublica: Cada gesto cuenta para frenar el virus. No bajes la guardia. Pon en práctica las \#6M para reducir el riesgo de contagio de \#Covid19: 1 Mascarilla 2 Metros 3 Manos 4 Más ventilación 5 Menos contactos $6 \mathrm{Me}$ quedo en casa si tengo síntomas Si tú te proteges, cuidas del resto (https://twitter.com/saludpublicaes/status/1372943697680113664, 19-03-2021). 
(18) @Sanidadgob:España ha realizado más de 14,5 millones de pruebas diagnósticas desde el inicio de la pandemia, de las cuales 10,8 millones son \#PCR En la última semana, se han realizado una media de 127.963 pruebas diagnósticas al día, 102.753 de ellas, \#PCR https://t.co/bw4TksH5VO [enlace a pdf sobre n. PCRs realizadas hasta el 08-10-2020] (https://twitter.com/sanidadgob/status/1315653487401807873 12-10-2020).

Independientemente de su composición, las etiquetas analizadas se caracterizan por la concisión, la simplicidad sintáctica y la densidad semántica. Se nota el recurso frecuente a fórmulas breves, que se apoyan en sintagmas escuetos, con dos o tres elementos fusionados. En general, no se trata de fórmulas demasiado creativas, lo cual parece adecuado en un tipo de comunicación que busca llegar al destinatario de forma clara, directa y transparente. En cuanto al contenido, destacan los mensajes positivos que derivan del significado de palabras como "seguro" o la colocación "parar unidos", y que evocan seguridad, unidad y fuerza. De hecho, vehiculan mensajes que promueven una imagen positiva del gobierno y de las medidas adoptadas, como puede ser la estrategia de vacunación. Por otra parte, los que contienen actos declarativos y directivos atenúan los posibles efectos negativos en el destinatario a través del empleo de los pronombres personales con valor inclusivo, con los que las autoridades se acercan al ciudadano para afirmar que contra el virus la responsabilidad es de todos; y mediante fórmulas más creativas, dirigidas en algunos casos a los más jóvenes, a pesar de que pueden resultar algo ambiguas. En definitiva, los más empleados pretenden informar y persuadir al destinatario del mensaje a adoptar o no adoptar ciertos comportamientos, que deben inferirse del contenido mismo de la etiqueta, del contexto lingüístico y multimodal en el que se incluye y de los supuestos compartidos con las instituciones y la sociedad sobre la pandemia.

\section{Conclusiones}

El análisis llevado a cabo nos permite dar respuesta a las cuestiones planteadas al inicio de este estudio. En primer lugar, es posible afirmar que los hashtags son frecuentes en todos los perfiles analizados, en particular, en los del perfil de Salud Pública. Se trata, en general, de etiquetas que se repiten en todos los perfiles, a pesar de que Salud Pública hace un uso más diversificado del dispositivo. Las etiquetas más frecuentes coinciden con los términos y expresiones más habituales referidos a la enfermedad y a la vacuna, y con los títulos de las campañas del gobierno, empleadas durante las navidades y en los momentos de mayor gravedad de la crisis sanitaria. Con pocas diferencias entre los tres perfiles, muchas de las etiquetas empleadas 
suelen apoyarse en sustantivos aislados o en sintagmas nominales y verbales que tematizan el contenido del tuit, haciendo referencia a los temas relacionados con la gestión de la crisis que el gobierno pretende poner en la agenda mediática (cfr. Castillo-Esparcia et al., 2020).

Por otra parte, las etiquetas analizadas establecen relaciones internas con los elementos lingüísticos que aparecen en los tuits, y externas, cuando hacen referencia al momento específico en el que inicia la entrada en vigor de determinadas medidas para frenar los contagios o durante la campaña de vacunación. Estas se convierten no solo en mecanismos para contribuir a la difusión de información dirigida a la ciudadanía, sino que constituyen también marcas de la enunciación dentro de actos persuasivos, que buscan fomentar ciertos comportamientos y promover el contenido de las campañas en el microblog, en paralelo a como se hace en otros medios. No en vano, la mayor parte de las etiquetas hace referencia al plan de vacunación y a las medidas de contención de contagios, dentro del encuadre predominante de la comunicación del gobierno ante la crisis. Asimismo, combinan contenidos que apelan a la razón pero también a las emociones, con el doble objetivo de captar la atención de los distintos públicos a los que van dirigidas las informaciones y viralizar los conceptos y consignas de la estrategia comunicativa adoptada por el gobierno en Twitter. En este sentido, un aspecto que no se ha podido abordar aquí por cuestiones de espacio, pero que creemos que merece ser investigado es el del impacto que pueden tener estos dispositivos en la interacción entre ciudadanos e instituciones en esta red social. Indagar cómo los usuarios reutilizan estos mismos hashtags para, por ejemplo, formular preguntas o peticiones a las instituciones o para añadir informaciones puntuales basadas en su propia experiencia permitiría verificar también el grado de eficacia comunicativa de las etiquetas empleadas en la gestión comunicativa de la crisis en esta red social.

\section{BibLIOGRAFía}

BANI, Sara (2020): «La comunicación institucional en las redes sociales: los cuerpos de seguridad en Twitter $\gg$, Cuadernos AISPI, 16, 2, pp. 63-86.

Calleja, María Antonia (2020): «Contagio del ébola en España: ejemplo de cómo no comunicar una crisis», Cuadernos Artesanos de Comunicación, 178, pp. 83-99.

Camilleri, Mark A. (ed.) (2020): Strategic Corporate Communication in the Digital Age, Emerald, Bingley.

Carratalá, Adolfo y María Galán (2016): «Estrategias comunicativas en Twitter de los ayuntamientos españoles gobernados por plataformas ciudadanas », Revista F@ro,2, 4,pp.126-150. 
Casero-Ripollés, Andreu (2020): «Impact of Covid-19 on the media system. Communicative and democratic consequences of news consumption during the outbreak», El profesional de la información, 29, 2, pp. 1-11.

Castillo Esparcia, Antonio, Ana Belén Fernández Souto e Iván Puentes Rivera (2020): «Comunicación política y Covid-19. Estrategias del Gobierno de España », El profesional de la información, 29, 4, pp.1-22.

Chadwick, Andrew (2013): The hybrid media system: Politics and power, Oxford, Oxford University Press.

Gallardo-Paúls, Beatriz y Salvador Enguix Oliver (2016): Pseudopolitica. El discurso político en las redes sociales, València, Universitat de València.

González Bengoechea, Aitor (2015): «Redes sociales y política: El uso comunicativo de Twitter por parte de los principales partidos políticos», Fòrum de recerca, 20, pp. 539-555.

Gutiérrez-Rubí, Antoni y Carles Pont-Sorribes (coords.) (2020): Comunicación politica en tiempos de coronavirus, Barcelona, Cátedra Ideograma-UPF.

Heyd, Theresa y Cornelius Puschmann (2017): «Hashtagging and functional shift: Adaptation and appropriation of the \#», Journal of Pragmatics, 116, pp. 51-63.

IbÁÑez PeIró, Ángel (2020): «La actividad informativa del Gobierno español durante la emergencia sanitaria provocada por el coronavirus, COVID-19», Revista Española de Comunicación en Salud, 1, pp. 304-318.

López EIre, Antonio (1998): La Retórica en la publicidad, Madrid, Arco / Libros.

López-GARCía, Guillermo (2020): «Vigilar y castigar: el papel de militares, policías y guardias civiles en la comunicación de la crisis del Covid-19 en España », El profesional de la información, 29, 3, pp. 1-15.

Mancera Rueda, Ana y Ana Pano Alamán (2013): «Nuevas dinámicas discursivas de la comunicación política en Twitter», Círculo de Lingüistica aplicada a la Comunicación, 56, pp. 53-80.

Mancera Rueda, Ana y Uta Helfrich (2014): «La crisis en 140 caracteres: el discurso propagandístico en la red social Twitter», Cultura, Lenguaje y Representación, vol. XII, pp. 59-86.

Mancera Rueda, Ana y Ana Pano Alamán (2015): «Valores sintáctico-discursivos de las etiquetas en Twitter», Círculo de Lingüistica aplicada a la Comunicación, 64, pp. 58-83.

Más, Lluís y Frederic Guerrero (2019): «The use of hashtags as a political branding strategy », Revista Internacional de Relaciones Públicas, vol. IX, 17, pp. 5-24.

MenNa, Laura (2012): «Nuevas formas de significación en red: el uso de las \#etiquetas en el movimiento 15M», Estudios de Lingüistica del Español, 34, pp. 
1-61. En línea: http://elies.rediris.es/elies34/Tesina_L-Menna.pdf [22-052021].

Moreno, Emilio (2008): «Gestión de la información y la comunicación en emergencias, desastres y crisis sanitarias», Emergencias: Revista de la Sociedad Española de Medicina de Urgencias y Emergencias, 20 (2), pp. 117-124.

Pano Alamán, Ana (2020): «La política del hashtag en Twitter», Vivat Academia, 152, pp. 49-68.

Pulido-Polo, Marta, Víctor Hernández-Santaolalla y Ana lozaNO-GonZÁLEZ (2021): «Uso institucional de Twitter para combatir la infodemia causada por la crisis sanitaria de la Covid-19», El profesional de la información, 30, 1, pp. 1-15.

SAlAZAR, Eduardo (2017): «Hashtags 2.0 - An Annotated History of the Hashtag and a Window to its Future», Icono 14, 15 (2), pp. 16-54.

Sсотт, Kate (2015): «The pragmatics of hashtags: Inference and conversational style on Twitter», Journal of Pragmatics, 81, pp. 8-20.

Suau-Gomila, Guillem, Salvador Percastre, Gemma Palà y Carles Pont-SoRRIBES (2017): «Análisis de la comunicación de emergencias en Twitter. El caso del Ébola en España», en Javier Sierra y Sheila Liberal (eds.), Uso y aplicación de las redes sociales en el mundo audiovisual y publicitario, Madrid, McGrawHill, pp. 119-130.

Tirado, Alejandra (2018): «El papel de Twitter en la estrategia de comunicación institucional en situaciones de emergencia: El caso de los atentados terroristas de Barcelona de 2017», Fòrum de Recerca, 23, pp. 31-49.

Zappavigna, Michelle (2011): «Ambient affiliation: a linguistic perspective on Twitter», New Media Society, 13(5), pp. 788-806.

Fecha de recepción: 28 de junio de 2021 Fecha de aceptación: 12 de noviembre de 2021 